\title{
Responsabilidade Social Empresarial e Economia Solidária: a Construção Social da Empresa no Brasil ${ }^{1}$
}

\author{
Caroline da Graça Jacques ${ }^{2}$ \\ Melissa Gabriela Barcelos ${ }^{3}$ \\ Maria Soledad Etcheverry Orchard ${ }^{4}$
}

\begin{abstract}
RESUMO
O artigo expõe algumas das transformações que atingem o setor empresarial contemporâneo em sua busca por legitimidade junto a setores da sociedade brasileira. Questionamos se os programas de Responsabilidade Social Empresarial (RSE) indicam lógicas diferentes da busca pela maximização dos lucros corporativos. Como forma de ilustrar esse debate, realizamos um estudo de caso no Instituto Consulado da Mulher, criado pela marca Consul de Eletrodomésticos para o cenário sociopolítico brasileiro. A abordagem sociológica dos mercados e das empresas, que ressalta as dimensões social, cultural e política da ação econômica indica que as empresas são construções sociais. Nesse sentido, pode-se compreender a RSE e suas singularidades no contexto nacional pela emergência de políticas sociais liberais.
\end{abstract}

Palavras-chave: Responsabilidade Social Empresarial; Construção Social da Empresa, Economia Solidária, Nova Sociologia Econômica.

\begin{abstract}
The article outlines some changes that affect enterprises in the way for the construction of legitimacy in Brazil. We question if corporate social responsibility programs can indicate different logics to pursuit corporate profits. To illustrate this debate, we conducted a case study at the "Instituto Consulado da Mulher" (Consulate Women's Institute), created by Consul home appliances brand (Whirlpool Corporation) for Brazilian socio-political scenario. The sociological approach of markets and enterprises, which highlights the social, cultural and political dimensions of economic action indicates that companies are social constructions. Therefore, we understand CSR and its singularities in the national context for the emergence of liberal social policies.
\end{abstract}

Key Words: Corporate Social Responsibility; Social Construction of Enterprises, Social Economy, New Economic Sociology.

\footnotetext{
${ }^{1} \mathrm{O}$ artigo foi previamente debatido no GT de Sociologia Econômica, coordenado pelo Prof. Dr. Cristiano Fonseca Monteiro (UFF) e Prof. Dr. Marcelo Sampaio Carneiro (UFMA) na XV Reunião da Sociedade Brasileira de Sociologia, no inverno de 2011, em Curitiba/PR.

2 Doutoranda pelo Programa de Pós-Graduação em Sociologia Política da Universidade Federal de Santa Catarina (UFSC). Pesquisadora do Nusmer - Núcleo de Estudo Sociológicos dos Mercados, que foi coordenado pela Prof ${ }^{\mathrm{a}} \operatorname{Dr}^{\mathrm{a}}$ Cécile Hélène Jeanne Raud (in memoriam) e $\operatorname{Prof}^{\mathrm{a}} \operatorname{Dr}^{\mathrm{a}}$ Maria Soledad Etcheverry Orchard. Endereço: Campus Universitário Reitor João David Ferreira Lima - Trindade - CEP 88040-900 Florianópolis Santa Catarina - Brasil. E-mail: caroljacques24@gmail.com

${ }^{3}$ Mestre pelo Programa de Pós Graduação em Sociologia Política da Universidade Federal de Santa Catarina (UFSC). Pesquisadora do LASTRO - Laboratório de Sociologia do Trabalho (UFSC) coordenado pelo Prof ${ }^{\circ}$ Dr $^{\circ}$ Ricardo Gaspar Muller.

${ }^{4}$ Doutora em Sociologia e Antropologia pela Universidade Federal do Rio de Janeiro (UFRJ). Professora do Departamento de Sociologia Política da Universidade Federal de Santa Catarina (UFSC).
} 


\section{INTRODUÇÃO}

Desde a década de 1980, o setor empresarial brasileiro vem incorporando e divulgando, entre suas atividades tradicionais de produção, distribuição de bens e pagamentos de tributos, ações voltadas para a promoção de algum tipo benefício para a sociedade. No início, as atividades poderiam ser explicadas mediante a posição de atores-chave na empresa, sob a justificação de uma inclinação ética ou moral de seus dirigentes ${ }^{5}$. No entanto, ao longo dos anos 90 e início do novo milênio, as empresas passam a sistematizar e a racionalizar suas ações sociais: criam departamentos internos de responsabilidade social empresarial (doravante RSE), solicitam consultorias especializadas a fim de adequar seus "investimentos sociais" às operações das marcas, apoiam ações públicas de incentivo ao desenvolvimento local, além de criarem seus próprios institutos e fundações para operarem nas políticas públicas ${ }^{6}$.

Do ponto de vista sociológico, convém questionar se as empresas buscam através do desenvolvimento da RSE, apenas um maior retorno para seus acionistas em termos de lucratividade. A afirmação equivale a dizer que, segundo a abordagem da Sociologia Econômica, a empresa contemporânea deve ser compreendida em termos complexos, ou seja, nas múltiplas relações que estabelece com a dinâmica da sociedade (SAINSAULIEU, 1987, CAPPELLIN et al, 2002; KIRSCHNER, 2009). Ao longo de nossa explanação pretendemos expor nossos argumentos a favor de uma leitura complexa da empresa, ou seja, uma instituição que precisa interagir com atores sociais que apresentam demandas específicas e que, no limite, lhes garante estabilidade no curso de suas operações.

De acordo com as análises de Kirschner (2006; 2009), a partir de meados de 1980, paralelamente ao enxugamento do modelo de Estado de Bem-Estar Social e o ápice do neoliberalismo, a sociedade reclamou das empresas mais comprometimento social e ambiental, assim como um comportamento mais ético. Para a autora (2009, p. 100), a empresa atualmente "precisa ser considerada extramuros para fins de análise, porque tem que conciliar seus interesses com os interesses dos diferentes atores sociopolíticos com os quais interage". Por outro lado, a RSE tem sido incentivada pelo Estado.

\footnotetext{
${ }^{5}$ A noção de ator-chave na empresa remete-se ao papel que determinados agentes detêm para estabelecer e por em curso mudanças nas instituições. Nesse sentido, são mulheres e homens que possuem poder, mas, sobretudo, autoridade legitima para tomar decisões relevantes para o projeto da empresa. São, portanto, atores reconhecidos pelo grupo, também denominados pela ciência da gestão como líderes, indivíduos autorizados e legítimos para estabelecer mudanças e transformações nos processos das empresas (BERNOUX, 1995; KIRSCHNER, 2009).

${ }^{6}$ Algumas expressões foram destacadas pelas aspas para indicar que são categorias nativas (GEERTZ, 1980) da literatura das ciências de gestão e/ou típicas dos documentos institucionais das empresas. A ideia de RSE tem sido debatida por várias matrizes teóricas, sobretudo de forma interdisciplinar.
} 
Em uma perspectiva crítica, Cappelin (2000, p. 266) argumenta que, no Brasil, as experiências a respeito do engajamento das empresas em RSE são realidades recentes, “(...) a responsabilidade social, a igualdade de oportunidades entre homens e mulheres é debate entre os empresários e suas direções, porém estes debates são dispersos e ainda tímidos (...). A promoção de políticas de fomento da igualdade entre homens e mulheres no mercado de trabalho tem sido agenda de diferentes atores sociais desde os anos de 1970: feministas, movimentos de mulheres trabalhadoras, centrais sindicais, organizações não governamentais (ONGS), centros de pesquisas universitárias, assim como instituições públicas de planejamento de políticas de emprego. A autora também observa que em tempos de flexibilização e reestruturação dos direitos trabalhistas, paralelo ao discurso da prática de RSE, diversas federações e associações empresariais agem pressionando o Estado para que os direitos trabalhistas sejam retirados da legislação nacional e que as negociações de direitos sejam realizadas coletivamente de forma direta com os trabalhadores (CAPPELLIN, 2002).

De fato, em âmbito internacional, alguns autores veem a RSE apenas como modismo de gestão, outros já a compreendem como um quadro de soft regulation, que traz novas exigências às empresas, como a valorização dos direitos humanos e a promoção do desenvolvimento social (Crane et al. 2008; John Ruggie, 2013). Embora não haja consenso entre as múltiplas abordagens que se dedicam a compreender e explicar a RSE (Cappellin et al, 2002; Allouche et al, 2004; Garriga \& Melé, 2004), compreendemos o fenômeno como uma forma da empresa promover, em vários níveis, um diálogo com atores relevantes para a própria estabilidade a médio e longo prazo dos empreendimentos econômicos dentro da lógica da acumulação de recursos econômicos. Entendemos que as iniciativas de RSE não são atividades e posturas gerenciais que se desenvolveram unilateralmente, do interior das fábricas para o seu meio exterior, como ações autônomas das empresas. Nesse sentido, é relevante ressaltar os aspectos sociais, políticos e econômicos que deram ensejo ao surgimento da temática e, sobretudo, quais são as formas de regulação existentes hoje para tais programas.

Por outro lado, para o analista atento é fundamental relacionar o surgimento da RSE com as transformações que atingem o mundo do trabalho, tais como a flexibilização das leis trabalhistas e do trabalho formal, a crise de representatividade dos sindicatos, os desafios ambientais atuais, a hipertrofia do sistema financeiro, sua falta de regulamentação e a crise no modelo de Estado universalista como o único garantidor de direitos de cidadania. 
Para ilustrar essa tensão política e econômica atual, focamos a institucionalização do principal programa de RSE da marca Consul de eletrodomésticos, presente na região de Joinville-SC. Trata-se, pois, de uma marca brasileira incorporada pela multinacional Whirlpool. A corporação é a principal fabricante mundial dos produtos de linha branca (direcionados para o âmbito doméstico como, fogões, máquinas de lavar, refrigeradores, etc.), e concentra $40 \%$ do mercado nacional do ramo, empregando cerca de 18 mil trabalhadores no Brasil (Jacques, 2010). No início da década de 2000, a norte americana Whirlpool adquire a maioria das ações da Multibrás, empresa nacional que até então fabricava os produtos da linha branca através das marcas Consul, Brastemp e Semmer. No ano de 2015, a Whirlpool é proprietária de 4 fábricas no território brasileiro, que servem ao mercado da América Latina, além de centros de "inovação tecnológica e de logística". Trata-se de uma empresa de capital aberto, com ações listadas na BMF Bovespa. Em relação ao tema da RSE, a Whirlpool já recebeu inúmeras premiações, sendo talvez, a mais importante, o fato de estar listada no Ranking "Melhores Empresas para se trabalhar" (Ed. Abril) desde o início da publicação da lista e que mede o "grau de satisfação e de felicidade" no ambiente laboral. O "relatório de sustentabilidade da organização" é publicado anualmente pela instituição e sintetiza as iniciativas em relação aos projetos de responsabilidade social e ambiental da empresa.

No entanto, o Instituto Consulado da Mulher é o recorte empírico de nossa pesquisa, um projeto social criado pela Consul em 2002, nas cidades onde a empresa possui indústrias e/ou escritórios: Rio Claro (SP), Joinville (SC), Manaus (AM) e São Paulo (SP). Com a criação dessa instituição, a empresa anuncia a promoção de um espaço para desenvolver a cidadania da mulher, através do acesso à informação e novas formas de organização do trabalho. Os projetos "Usinas do Trabalho" e "Mulher Empreendedora" desenvolvem atividades para a formação de grupos femininos com base nos princípios e metodologias da economia solidária e da autogestão. Trata-se, pois, de um espaço dedicado a "assessorar" empreendimentos populares organizados por mulheres de baixa escolaridade, com o objetivo maior de gerar acesso à renda e a qualidade de vida (WHIRLPOOL, 2007/2008).

Interessa-nos, nessa comunicação, desvendar o aparente paradoxo entre o investimento direcionado pela multinacional Whirlpool - uma empresa que se constrói com base em cadeias produtivas globais - em projetos sociais que fomentam um outro olhar sobre a forma de se conceber a economia, a organização do trabalho e as relações trabalhistas. Falamos em um aparente paradoxo, pois numa visão economicista, a lógica da empresa estaria atrelada somente ao processo produtivo que privilegia, sobretudo, a acumulação do capital. No 
entanto, conforme a abordagem da sociologia econômica e o imperativo de construção social dos mercados, compreende-se a relação existente entre a esfera econômica e o surgimento de uma agenda ética compartilhada para o desenvolvimento social, da qual as ações de RSE alegam fazer parte.

Nosso estudo mostra que a Economia Solidária, através dos pequenos grupos femininos formados no interior das casas do Instituto Consulado da Mulher, passa, portanto, a receber recursos financeiros e técnicos oriundos do setor privado. Ao longo do ano de 2009, a Whirlpool investiu cerca de 3,3 milhões de reais em projetos de geração de renda para mulheres a partir da metodologia da Economia Solidária; além de integrar e fortalecer, na região de Joinville, o Fórum de Economia Solidária do Norte Catarinense - um espaço dedicado a discussão política e deliberações públicas sobre a temática (JACQUES, 2007; 2010).

\section{METODOLOGIA}

A pesquisa de estudo de caso apoiou-se em entrevistas semidirigidas, pesquisas documentais e observação participante. Os dados qualitativos foram estruturados com base na análise de conteúdo, na vertente francesa, proposta por Laurence Bardin (2011).

No total, 17 entrevistas foram direcionadas para dois grupos distintos: os (as) funcionários (as) do Instituto Consulado da Mulher e às mulheres dos grupos de Economia Solidária "assessorados" pelo Instituto Consulado da Mulher na cidade de Joinville. De fato, a entrevista semidirigida permite, por um lado, que o próprio entrevistado estruture o seu pensamento e o seu discurso. Por outro lado, permite uma margem de manobra para que o (a) entrevistador (a) siga o curso das respostas com base na definição de tópicos estruturantes do objeto de estudo (ALBARELLO et al, 1997). Um dos dirigentes do instituto e também exfuncionários da Whirlpool do "setor de produção" concedeu-nos as principais informações relativas ao surgimento e foco do projeto. Ademais foram realizadas entrevistas com duas "educadoras sociais" que atuam diretamente com os grupos de Economia Solidária e 14 mulheres integrantes dos grupos apoiados pela instituição. O Fórum de Economia Solidária do Norte Catarinense foi o local onde realizamos a observação participante. Por fim, as pesquisas documentais foram realizadas nos textos que compõe a chamada "governança corporativa" da empresa: relatórios de atividades sociais e código de ética para os (as) empregados (as) da firma. 
A análise de conteúdo busca compreender os discursos do não-dito. Portanto, as categorias analíticas foram destacadas pela abordagem e pelo rigor científico que associa a objetividade e a subjetividade (BARDIN, 2011). Direcionamos nosso olhar teórico para os autores do campo da Sociologia Econômica e da Nova Sociologia Econômica que nos auxiliaram a entender os mercados como estruturas institucionais socialmente construídas assim como as empresas, compreendidas como instituições que não estão acima da vida em sociedade, de seus preceitos e exigências éticas (RAUD-MATTEDI, 2005, STEINER, 2006). As relações sociais, portanto, são fatores estruturantes das trocas entre os atores presentes nos mercados. Nesse sentido, destaca-se a importância dos fatores extra econômicos no funcionamento da economia real. Essa perspectiva só é possível porque integra a abordagem epistemológica do paradigma relacional que se contrapõe ao paradigma individualista (individualismo metodológico/economia neoclássica) (RAUD, 1999).

Do ponto de vista político, partimos da constatação levantada, sobretudo, por Gomes (2002) e Iglesias (2005). O atual movimento das empresas com as ações de responsabilidade social integra os esforços dos Estados, do setor empresarial e também da sociedade civil para a consolidação de uma nova concepção sobre o desenvolvimento socioeconômico. Uma nova "agenda ética" para as empresas, portanto, não diz respeito exclusivamente às ações econômicas, mas, à consolidação de uma nova forma de gerir os esforços para as políticas sociais e o desenvolvimento socioeconômico. As novas lógicas na construção social da empresa, advém, sobretudo, da noção liberal de uma responsabilidade partilhada com as empresas e não mais na universalidade dos direitos de cidadania garantidos unicamente pelo Estado.

\section{RESPONSABILIDADE SOCIAL EMPRESARIAL E GOVERNANÇA CORPORATIVA: O EXEMPLO DA CONSUL}

Quando o Consulado da Mulher surgiu, na cidade de Joinville, a ação social não passava de um pequeno espaço para a promoção da sociabilidade e convivência feminina. Ações ainda tímidas se limitavam a cursos de artesanatos, culinária, ensino da informática e palestras sobre autoestima para moradoras da comunidade, funcionárias da empresa e consumidoras da marca Consul. O ano era 2002 e, no Brasil, o tema da RSE já figurava pelas mídias, sobretudo em virtude do esforço de algumas entidades do campo empresarial e do 
chamado terceiro setor em evidenciar a importância da associação de princípios éticos e socialmente relevantes com a lógica mercantil. ${ }^{7}$

No entanto, a criação do Instituto Consulado da Mulher propriamente não inaugura uma postura de RSE: desde a década de 1960 a Consul manteve parcerias com o SENAI (Serviço Nacional de Aprendizagem Industrial) para o desenvolvimento de cursos de formação de mão-de-obra principalmente para jovens iniciantes no mercado de trabalho no setor industrial. Além dessa atuação direta para a qualificação do trabalhador, que segundo Goldstein (2006) e Torquato (2007) marca o início da RSE no cenário nacional, a empresa envolvia-se em atividades sociais de forma não estruturada como, por exemplo, manutenção de praças e doação de eletrodomésticos para entidades assistencialistas. No entanto, de acordo com as entrevistas realizadas em nossa pesquisa, entende-se que foi a constatação do alto investimento envolvido nessas atividades desfocadas e a ausência de uma perspectiva de transformação social, para além do caráter da simples doação, que motivou a empresa a estruturar e a institucionalizar um programa de RSE com base nos princípios da Economia Solidária.

Contudo, a origem do Consulado da Mulher, no entanto, se deu quando por solicitação da alta gerência administrativa, um "grupo de ação local" fosse estabelecido, entre setores distintos da fábrica (gerenciais e operacionais) a fim de se criar as linhas mestras do programa. Em pesquisas anteriores, focamos nossos esforços analíticos para compreender as motivações do empresariado no desenvolvimento das chamadas práticas de RSE. Embora já tenhamos tratado deste tema em textos anteriores (JACQUES, 2007; 2010b) convém ressaltar que, segundo a Whirlpool, a principal motivação em fomentar programas de RSE é estreitar o vínculo com a sociedade onde a empresa está inserida e, ainda, uma forma inovadora de fazer com que os lucros corporativos retornem ao meio social, para além da geração de emprego e pagamento de tributos.

Assim, as entrevistas balizadas pelas análises documentais, indicam que a origem do processo de institucionalização do programa de RSE, está por um lado, associado com a formalização de grupos, no interior da empresa, destinado a pensar as ações de RSE e, por outro lado, a partir da contratação de uma consultoria especializada em temas relevantes para o foco social da entidade. ${ }^{8}$ Para a criação do Consulado da Mulher, um "conselho de

\footnotetext{
${ }^{7}$ As principais entidades que atuam desde então são o Ibase (Instituto Brasileiro de Análises Sociais e Econômicas), o GIFE (Grupo de Instituto, Fundações e Empresas), o Instituto Ethos e o CEBDS (Conselho Empresarial Brasileiro para o desenvolvimento Sustentável).

${ }^{8}$ A consultoria que a então Multibrás SA contratou fora uma equipe de profissionais e professores da FURB (Universidade de Blumenau) com formação nas áreas de Antropologia e Sociologia Política para que o corpo
} 
responsabilidade social", composto por funcionários chefes de diversas áreas da companhia e presidido pelo diretor geral da empresa fora estabelecido e um "comitê multifuncional de responsabilidade social", coordenado pela diretoria jurídica e de "relações externas" e integrado por representantes de várias áreas da empresa se reuniam periodicamente para pensar e organizar as atuações da entidade. Conforme o documento é atribuição do comitê multifuncional assegurar que cada segmento da empresa adote "uma gestão direcionada à responsabilidade social", o que inclui inclusive a contratação dos fornecedores que devem estar alinhados com as prerrogativas da sustentabilidade e da ética nos negócios (JACQUES, 2007).

Portanto, as primeiras ações de RSE - doação de eletrodomésticos para entidades comunitárias, manutenção de parques e praças da cidade e treinamentos para os (as) trabalhadores(as) - correspondem a uma inclinação primária da empresa com a dinâmica da sociedade. A criação do Consulado da Mulher e o estabelecimento dos princípios da Economia Solidária e da autogestão nas atividades da entidade demonstram o desenvolvimento da postura da empresa em adequar os investimentos para um foco exclusivo qual seja, geração de renda para mulheres. Se, em um primeiro momento as ações são de cunho assistencialista e descoladas de planejamentos, foi com o surgimento do programa que a empresa passa a definir seu público-alvo, metodologia de funcionamento e aplicação de recursos financeiros. Falamos então de uma racionalização das práticas sociais da empresa, posto que se configuram como ações sistemáticas destinadas à consecução de metas definidas a priori.

É fundamental ressaltar que a postura da empresa em evidenciar uma gestão voltada para os lemas da ética nos negócios, da sustentabilidade e da responsabilidade social acontece concomitante os processos de fusão entre as empresas Multibrás e a multinacional Whirlpool, da internacionalização das marcas Consul e Brastemp que avança durante a década de 2000 e, portanto, de uma maior visibilidade da empresa nos mercados financeiros. No Brasil, as ações da Whirlpool fazem parte da Bolsa de Valores (BM\&FBovespa), cujo princípio da sustentabilidade é anunciado como uma gestão capaz de agregar valor às companhias. Embora a Whirlpool não faça parte do Índice de Sustentabilidade Empresarial (ISE BM\&F Bovespa) a empresa dispõe de um conjunto de práticas e instrumentos que são reconhecidos como legítimos no campo da RSE: elaboração de código de ética para funcionários e fornecedores,

técnico da entidade recebesse orientações nas áreas de Economia Solidária, Empreendedorismo e Educação de Gênero, temas centrais das atividades do grupo. 
publicação de relatórios de sustentabilidade para comunicar a postura da empresa e investimentos na comunidade através do lema da RSE.

Assim, ressaltamos que a RSE, entendida como a racionalização das práticas sociais, bem como ferramentas de "transparência organizacional", por exemplo, a elaboração de códigos de conduta para trabalhadores e fornecedores e relatórios de sustentabilidade faz parte da chamada "governança corporativa". Do ponto de vista da sociologia econômica e conforme esclarece Grün (2009), o termo refere-se a possibilidade de se pensar o mercado financeiro como um espaço análogo à esfera cívica, no qual pode haver transparência, respeito pelos direitos das minorias e democracia. Na prática, conforme o autor, a governança corporativa permitiria canalizar capital de terceiros para financiar as empresas: um bálsamo eficiente para um problema crucial da economia brasileira que precisa lidar com a falta de capital para estruturar suas expansões na intensidade que a economia nacional exige. Assim, uma vez instaurada a boa governança corporativa, os (as) investidores (as) tenderiam a confiar e a direcionar suas aplicações em ações das empresas (Grün, 2009).

Por outro lado, o advento da RSE está diretamente associado com a chamada "teoria dos stakeholders" que anuncia a possibilidade do equilíbrio das demandas dos diversos públicos afetados pela companhia ou que podem vir a afetá-la. As "partes interessadas" seriam, pois, o próprio tecido social no qual as empresas estão inseridas e sobre o qual emergem os atores com os quais as empresas buscam promover um diálogo construtivo - ou afirmam que o fazem.

Autores franceses como Allouche et al (2004, p.2407, tradução nossa) entendem que, numa concepção atual, a RSE integra três elementos: honrar as obrigações em relação a pluralidade das "partes interessadas", responder às demandas sociais ditadas pelo meio socioeconômico e por fim, utilizar o conceito e seu campo de aplicação como "ferramenta de gestão". O meio ambiente, a comunidade onde a empresa ou a fábrica está instalada, os clientes, os trabalhadores, os fornecedores, os acionistas minoritários e as instâncias públicas são vistos, portanto, como atores relevantes para a própria estabilidade da empresa. Seguimos ainda os autores para entender uma crítica que se faz ao modelo de gestão da RSE: os supostos beneficiários pelo exercício concreto das práticas são, na melhor das hipóteses, o conjunto dos stakeholders, sem consideração explícita aos trabalhadores e às trabalhadoras (ou seus dependentes diretos). Nesse sentido, o que se pode destacar é que as políticas 
internas de recursos humanos permanecem à margem ou mesmo oculta nos discursos e nas práticas. ${ }^{9}$

Dentro de uma perspectiva política dos mercados, os resultados das entrevistas e das análises de documentos evidencia que a RSE integra uma concepção de controle (FLIGSTEIN, 2001), ou seja, é simultaneamente uma visão de mundo que permite aos atores interpretar as ações dos outros atores e um reflexo da forma como o mercado está estruturado, um "saber local" (GEERTZ, 1980 apud FLIGSTEIN, 2001). O Estado, por sua vez, conforme Fligstein (2001) deve ratificar, impulsionar ou, no mínimo não se opor à concepção de controle. Consoante uma abordagem política da ação econômica entendemos que os atores econômicos pertencem a um mundo obscuro, onde não se pode identificar quais ações terão certas consequências, então seus esforços são no sentido de interpretar essa obscuridade, motivando e determinando o rumo da ação, ou seja, justificando-a. Na dinâmica dos mercados, conforme Fligstein (2001, p. 31) "o objetivo da ação é assegurar a sobrevivência da empresa. (...) A ação é, portanto, direcionada no sentido da criação de mundos estáveis". A criação de um programa de RSE, conforme o caso pesquisado, integrando trabalhadores (as) e gerentes sob uma mesma matriz ideológica - o imperativo da sustentabilidade, da responsabilidade e do desenvolvimento social - estabelece uma visão especifica do agir na própria empresa e nos mercados. De fato, a criação de departamentos internos de RSE, relatórios de sustentabilidade, código de conduta para trabalhadores/fornecedores e certificações do ramo são formas de se estabelecer um tipo de identidade coletiva, ao mesmo tempo em que nas empresas estabelecidas opera como um acordo político, definindo alianças entre empresas dependentes (cadeias de suprimentos). Se hoje a RSE pode ser identificada como uma ferramenta de gestão, a sua origem, no entanto, está claramente associada com a tentativa das empresas de desenvolver uma atitude mais proativa de gerenciamento de risco à reputação, em particular face às grandes contestações do movimento ambientalista da década de 70 e 80 (TORRES, 2002; DUARTE \& JACQUES, 2010; BENNETT, 2010).

Atualmente, a criação dos selos certificadores no âmbito da responsabilidade social, segurança dos trabalhadores e gestão ambiental são fortes indícios de novas lógicas que orientam os atores no estabelecimento das relações mercantis. Como bem salientou o trabalho de Almeida (2006), as normas de responsabilidade social interna, como a SA 8000 (Social Accontability International), operam de maneira a criar uma plataforma padrão de conduta

\footnotetext{
${ }^{9}$ No entanto, de acordo com a pesquisa Market Analysis (2005) sobre a percepção da RSE junto ao consumidor brasileiro, do ponto de vista deste, a empresa só pode ser considerada socialmente responsável se, sobretudo, respeita os direitos dos trabalhadores, tratando-os de forma justa.
} 
nas organizações que, sobretudo, são imperativos das empresas maiores (contratantes), no seio das cadeias de produção ${ }^{10}$. A não observância de tais certificações pode, inclusive, romper relações de compra e venda entre atores nos mercados.

Ainda segundo Fligstein (2001) a percepção dos atores sobre a estrutura social afeta diretamente as táticas que eles apresentam em favor da estabilidade para suas empresas. Se, conforme o autor, nos novos mercados a política se assemelha aos movimentos sociais, os atores tentam convencer as demais empresas a concordarem com sua concepção de mercado e se forem poderosas o bastante, tentarão impor seu ponto de vista. As concepções de controle podem vir a se tornar acordos políticos que trazem estabilidade de mercado às empresas. Sob essa ótica, os programas de responsabilidade social criados pelas organizações é um posicionamento das empresas em relação a própria estrutura social na qual a ação econômica está enraizada - no caso brasileiro, a problemática da exclusão social, proteção dos direitos humanos e do meio ambiente, a crise do desemprego, a contestação social e, sobretudo, a falta de confiança pública no mercado financeiro. É a reflexão sobre a estrutura social e sobre o contexto político e econômico que faz com que as empresas, em especial as de grande porte, operem no sentido de estabelecer seus programas de RSE com a marca do enraizamento social. No que se refere à Whirlpool, a reflexão sobre a problemática do acesso à renda para mulheres em situação de "vulnerabilidade social" fez com que a empresa criasse as linhas gerais de atuação do Instituto Consulado da Mulher.

\subsection{Consulado da Mulher, Economia Solidária e o Desenvolvimento de "tecnologias sociais reaplicáveis"}

Conforme nossa pesquisa indica, o foco de atuação do Consulado da Mulher, qual seja, "assessorar empreendimentos populares protagonizados por mulheres, com aporte de conhecimentos e recursos que viabilizem geração de renda e qualidade de vida" (Consulado da Mulher, s/d), fora escolhido "estrategicamente" pela empresa. Segundo a mesma, as mulheres são as principais consumidoras dos produtos da marca Consul no Brasil. Portanto, a iniciativa surge como uma forma de valorar a marca, através da sua aproximação com uma

\footnotetext{
10 A norma SA 8000 segue o modelo da ISO 9001 (qualidade dos processos, verificação e auditoria independente), mas refere-se às condições de trabalho no interior das empresas. As bases de formação da norma foram as prerrogativas da Organização Internacional do Trabalho (OIT), a Declaração Universal dos Direitos Humanos e a Declaração Universal dos Direitos da Criança da ONU (Para maiores esclarecimentos ver Almeida (2006) e Zacharias (2004).
} 
causa social relevante e socialmente reconhecida. Mas a criação da entidade, segundo a empresa, também se associa com uma posição com relação a valores, pela crença no papel da mulher na sociedade, como uma agente multiplicadora de conhecimentos:

A identificação do público feminino com os produtos da empresa - as mulheres representam $85 \%$ do total de consumidores das marcas Brastemp e Consul - e a preocupação em contribuir efetivamente para a melhoria da qualidade de vida das mulheres, levaram a Multibrás a criar o Instituto (WHIRLPOOL, 2004, p.36).

Acreditamos que a mulher é o pilar de sustentação da família, e agente transformador do seu entorno. Ao entender as oportunidades para ampliação de sua renda, ela percebe uma nova forma de viver e relacionar-se com o mundo, multiplicando esse conhecimento para seus filhos e demais familiares (Consulado da Mulher, s/d).

De fato, a criação do Consulado da Mulher não fora um empreendimento realizado pela Whirlpool Co. Esta acaba por herdar a entidade da antiga Multibrás SA, quando ocorre o processo de fusão no ano de 2006. Em 1994, Brastemp, Semer e Consul, empresas nacionais, associaram-se buscando fortalecimento e competitividade no mercado de linha branca, nascia assim a Multibrás SA, o maior grupo do segmento da América Latina. A nova empresa fazia parte então do Grupo Brasmotor que, em 1954, criou a Brastemp e que em 1976 já havia adquirido a Consul e a Embraco (Empresa Brasileiro de Compressores). No entanto, em janeiro de 2006, em leilão público na Bovespa, a Whirlpool adquiriu cerca de $95 \%$ do capital das duas empresas, tornando assim Multibrás e Embraco empresas subsidiárias da Whirlpool Co, um passo importante para que a norte americana viesse a se consolidar como a maior fabricante de eletrodomésticos em nível mundial. Desde a década de 80, a empresa já apresentava um comportamento orientado para sua internacionalização adquirindo empresas nos territórios do México, Canadá, China, África do Sul, Argentina e Brasil. Entretanto, foi com a aquisição da concorrente direta, a americana Maitag, que a Whirlpool tornou-se a líder do mercado da linha branca. São 72 fábricas e centros tecnológicos, 70 mil trabalhadores e uma receita de aproximadamente 19 bilhões de dólares (Whirlpool, s/d). No Brasil, a Whirlpool fabrica os produtos das marcas Consul, Brastemp e KitchenAid, a partir das quatro fábricas nas unidades de Joinville (SC), Rio Claro (SP) São Bernardo (SP) e Manaus (AM). A empresa integra ainda o grupo das 50 maiores em termos de faturamento, tendo registrado um lucro de US\$ 619 milhões em 2010. Com cerca de 18 mil funcionários, a filial brasileira da Whirlpool está entre as 35 maiores exportadoras brasileiras (WHIRLPOOL,2009/2010).

O Instituto Consulado da Mulher, criado então pela marca Consul com o apoio dos (as) trabalhadores (as) que formaram os "grupos de ação local" da então Multibrás é hoje uma 
OSCIP (Organização da Sociedade Civil de Interesse público). Trata-se de qualificação legal para que a entidade possa gozar simultaneamente do título de instituição de caráter social, sem fins lucrativos e manter um corpo de dirigentes e funcionários remunerados (Lei ${ }^{0} 7.980$ de 23 de março de 1999).

Com frequência, no âmbito da RSE, grandes empresas criam seus próprios institutos e fundações que por sua vez se apoiam nas prerrogativas dessa norma, também conhecida como Lei do Terceiro Setor. No Brasil, toda instituição sem fins lucrativos voltada para a educação ou à assistência social é imune aos impostos sobre a renda, sobre o patrimônio e sobre serviços. Especificamente no caso da RSE, as empresas que contribuem com ações socioambientais, como o apoio a projetos de OSCIPs, são permitidas deduções até o limite de $2 \%$ do lucro operacional, antes de computada a sua dedução. ${ }^{11}$

Desde a sua origem o Consulado da Mulher foca suas ações no público feminino. No entanto, ao longo dos anos, sua atuação foi se modificando. No início, nas casas do projeto, ocorriam oficinas que eram ministradas a partir do trabalho voluntário dos funcionários da empresa e moradores da cidade; o público-alvo eram mulheres de baixa escolaridade e renda. Com a entrada da Whirlpool na administração e controle da Multibrás e, portanto, na avaliação dos rumos da entidade, esta passa por transformações significativas. Nos anos de 2008 e 2009, o projeto recebe avaliações de "consultorias externas e independentes" e após esse processo as casas são gradativamente fechadas, ficando apenas quatro escritórios nas cidades onde a empresa detém as fábricas. Nessa ocasião verificamos a demissão de funcionários do quadro da entidade e, o que é mais grave, a retirada do espaço físico que era utilizado pelas mulheres dos grupos de geração de renda, como um local para a produção dos bens direcionados à comercialização. Entretanto, o discurso do Consulado da Mulher para justificar esses fatos é no sentido de direcionar suas ações para uma "efetiva transformação social”, através do direcionamento de esforços do projeto para o programa Usinas do Trabalho (WHIRLPOOL, 2009/2010). Assim, os empreendimentos assessorados pela entidade passam a não mais poder contar com o espaço físico, mas ainda podiam receber auxílio técnico, nomeadamente, o acesso à metodologia de apoio à economia solidária e os indicadores de avaliação aplicados pelo núcleo de "educadores sociais" da entidade.

\footnotetext{
${ }^{11}$ Portanto, poderão ser deduzidas do imposto devido à federação, as doações à entidades civis, legalmente constituídas no Brasil, sem fins lucrativos, que prestem serviços gratuitos em benefício dos (as) empregados (as) da pessoa jurídica e respectivos dependentes, ou em benefício da comunidade onde atuam, como no caso do Consulado da Mulher (Artigo 13, da Lei 9.249/95, combinado com a Instrução Normativa da Secretaria da Receita Federal 11/1996).
} 
Os "elementos modernizadores" da gestão de RSE propostos pela Whirlpool (2009/2010) marcam uma reestruturação na atuação local do Consulado da Mulher e enfatizam a expansão do projeto por todo o território nacional. Por outro lado, quando a Whirlpool adquire a Multibrás - na década de 2000 - há uma incorporação de padrões de RSE mundialmente reconhecidos. Em primeiro lugar, os relatórios de sustentabilidade passam a ser realizados segundo os critérios da Global Reporte Iniciative (GRI) e ainda, a empresa passa a ser signatária do Pacto Global proposto pela ONU. Tais elementos são fundamentais para a adequação do conjunto de práticas de RSE desenvolvidas no Brasil com as demais unidades da empresa a nível global. O modelo GRI para relatórios de sustentabilidade é, atualmente, a principal ferramenta de comunicação das práticas sociais, ambientais e econômicas das empresas para a sociedade. Trata-se de um relatório de prestação de contas que os consumidores, acionistas e integrantes de movimentos contestatórios podem acessar para conhecer as políticas das organizações. As diretrizes e os indicadores que compõe o documento se assemelham aos relatórios contábeis e, portanto, permitem que se compare os desempenhos numa escala temporal e também com empresas concorrentes.

Em 2009, a Whirlpool assina sua carta de adesão ao programa de responsabilidade social empresarial proposto pela Organização das Nações Unidas, o chamado Pacto Global. A inciativa reúne diretrizes normativas relacionadas à promoção dos direitos humanos, direitos do trabalho, combate à corrupção e proteção ambiental. Os princípios dispostos em 10 itens devem, conforme a ONU, balizar as ações do segmento empresarial voltadas tanto para a comunidade, como para funcionários, fornecedores e meio ambiente.

No entanto, as principais mudanças observadas em nossa pesquisa referem-se à forma como o Consulado da Mulher atua. O projeto Usinas do Trabalho já existia em menor grau quando o Consulado da Mulher atuava fisicamente nas casas, mas em menor grau. Trata-se de uma "tecnologia social", que enquanto metodologia poderia funcionar sem os espaços físicos da entidade. A proposta do Usinas do Trabalho é justamente estabelecer parcerias com outras organizações da sociedade, para que estas assumam a responsabilidade de monitoramento e orientação sobre os grupos de Economia Solidária. Na prática, o Consulado da Mulher disponibiliza a sua metodologia e os indicadores de avaliação desenvolvidos ao longo de sua trajetória, para grupos cooperados existentes em qualquer cidade brasileira, desde que acompanhados por uma entidade proponente (legalmente reconhecida como OSCIP). Além de disponibilizar as diretrizes da Economia Solidária e autogestão, também fornece meios de produção necessários como fogões, freezers, geladeiras e micro-ondas da marca Consul. 
Dessa forma, o projeto Usinas do Trabalho atingiu um alcance nacional. Trata-se da reaplicação de uma "tecnologia social" que leva o nome da empresa. Este conceito está em consonância com as propostas da RSE, pois se refere a práticas, métodos ou instrumentos capazes de solucionar algum tipo de "problema social" e que atenda aos quesitos de simplicidade, baixo custo, fácil aplicabilidade e geração de impacto social. As tecnologias sociais propõem uma interface entre saberes populares e conhecimentos científicos e sua eficácia, uma vez comprovada, deve ter o princípio de "replicabilidade". ${ }^{12}$

Até o primeiro semestre de 2010, oito estados brasileiros possuíam algum empreendimento apoiado pela iniciativa da Whirlpool, em processo de geração de renda. São dezoito estados brasileiros que integram a rede dos empreendimentos apoiados pela tecnologia social do Consulado da Mulher, - ultrapassando cem iniciativas de geração de renda. Sobre todo o processo de criação e mudança da entidade nos chama atenção o aspecto técnico-racional pelo qual o programa é visto pela empresa:

\begin{abstract}
Desde a criação, o desempenho do Consulado tem sido avaliado por meio de indicadores quantitativos e análises qualitativas. A Whirlpool Latin America acredita que, agora, o projeto está maduro o suficiente para oferecer também à marca Consul mais valor e reconhecimento, sem que exista o risco de ser visto como uma atitude de marketing descolada de seu propósito social (WHIRLPOOL, 2009/2010, p. 26).
\end{abstract}

Pode-se dizer que transformar o Consulado da Mulher, suas metodologias e indicadores de geração de renda em uma tecnologia social é, pois, uma forma de associar a marca com uma causa social em todo o cenário nacional; de levar a marca Consul para os bairros e comunidades onde antes não se podia chegar. O exemplo da Whirlpool e do Consulado da Mulher mostra como é possível a aquisição de uma nova forma de capital, nesse caso o capital simbólico, no sentido proposto por Bourdieu (1989), cuja eficácia simbólica reside na associação da marca à promoção do desenvolvimento socioeconômico de mulheres em condição de vulnerabilidade econômica e social.

\title{
3.2 Setor Público Não-Estatal, OSCIPs e Economia Solidária
}

O exemplo da criação do Consulado da Mulher pela Consul, sua adaptação à lei das OSCIPs e, portanto, a isenção físcal inerente ao investimento da empresa, às mudanças que perpassam a sua trajetória até a transformação do programa em uma "tecnologia social

\footnotetext{
${ }^{12}$ Para mais informações sobre o que são tecnologias sociais pode-se consultar o site da Fundação Banco do Brasil, que promove anualmente premiações e reconhecimento público dessas iniciativas em âmbito nacional. Disponível em: 〈http://www.fbb.org.br/portalfbb/tecnologiasocial> . acesso em: 20 maio 2014.
} 
replicável" está de acordo com o que Bresser-Pereira e Grau (1999) chamam de a emergência de um setor público não-estatal.

Do ponto de vista social-liberal, os autores defendem que, diante da crise do modelo social-burocrático do Estado e na busca por eficiência da administração pública, num contexto de globalização, o setor público não-estatal ou terceiro setor se apresenta como uma resposta viável para a execução de serviços sociais, antes limitados ao Estado. Os autores alegam que, com a crise do modelo social-burocrático e a ascensão da globalização, novas e mais eficientes modalidades de administração pública são exigidas: "as organizações de serviço público não estatais, que operam na área de oferta de serviços de educação, saúde e cultura com o financiamento do Estado" (idem, p. 16).

Paoli (2002), destaca que o contexto das ideias que dão respaldo para a emergência da ação solidária e responsável dos empresários se concentra no ideário do terceiro setor. Tal esfera, na opinião da autora, propõe um modelo de regulação social mais eficaz do que a ação tradicional do Estado. Nas palavras da autora:

A expansão do terceiro setor propõe de fato outro modelo para a resolução da questão social - centrado na generalização de competências civis descentralizadas, exercidas pelo ativismo civil voluntário em localidades específicas - e, portanto, uma outra relação com a capacidade política de concretizá-lo (PAOLI, 2002, p.380).

A posição da autora mostra-se bastante crítica às propostas de Bresser Pereira e Grau (op. cit.) alegando que se trata de uma versão onde a sociedade de direitos fundamentados na solidariedade coletiva reconfigura-se em uma sociedade organizada pela ação solidária privada, transformada em responsável pela execução de serviços sociais. Da mesma forma, Goldstein (2007) afirma que o grande problema nesse contexto é justamente a "desresponsabilização" do governo em garantir os direitos universais, transferindo para iniciativas particulares o poder de atender as demandas e carências sociais. Assim, como bem salientou Gros (2005) se tais demandas passam a ser incorporadas pela esfera privada, existe o risco de o acesso a serviços de educação, saúde e cultura, por exemplo, dependerem mais dos patrocinadores do que dos direitos universais.

Quando realizamos nossa inserção no campo para o desenvolvimento da pesquisa, verificamos que, na cidade de Joinville, o Consulado da Mulher é uma entidade central de apoio para os pequenos grupos femininos de economia solidária, mas também de articulação política. Em comunicações precedentes elaboramos uma descrição mais detalhada sobre a atuação do Consulado da Mulher junto ao Fórum de Economia Solidária nesse município (JACQUES, 2009; 2011; DUARTE E JACQUES, 2010). É relevante ressaltar, entretanto, que 
a rede intitulada "Fórum de Economia Solidária do Norte Catarinense" existe formalmente com o objetivo de estimular, nessa região, a criação de políticas públicas para a temática da Economia Solidária. Nesses eventos periódicos reúnem-se as integrantes dos empreendimentos solidários, instituições de apoio como universidades, fundações municipais, SEBRAE (Agência de apoio ao empreendedor e pequeno empresário), secretarias municipais do desenvolvimento social e entidades como o Instituto Consulado da Mulher para apoiar tecnicamente os empreendimentos e promover eventos e feiras para que ocorra a comercialização dos produtos. O Fórum de Economia Solidária da Região Norte integra as mobilizações em torno da Economia Solidaria no estado de Santa Catarina, em particular, através das plenárias estaduais do Fórum Catarinense de Economia solidária.

Essa rede criada a partir dos eventos do Fórum pode ser entendida como geradora do capital social (COLEMAN, 1990) e de capital social comunitário (DURSTON, 2000) que facilitam e promovem certas ações comuns aos empreendimentos autogestionários, em particular com relação aos cursos de formação em economia solidária, acesso ao crédito e a criação das oportunidades para a venda dos produtos. O instituto Consulado da Mulher, ao integrar essa conjuntura, estabelece um diálogo mais amplo com a agenda sociopolítica brasileira, que desde 2003 vem provendo avanços na área, em particular pela criação da Secretaria Nacional de Economia Solidária (SENAES).

Contudo, pode-se inferir que a participação do programa de RSE da marca Consul junto a rede de articulação em torno da Economia Solidária, está em consonância com um dos lemas da Teoria dos Stakholders. Ao participar das ações concretas de mobilização e fortalecimento dos princípios da economia solidária, em particular, a formação de grupos femininos com foco na geração de renda, o Consulado da Mulher aproxima-se de um de seus "públicos de interesse" de maior relevância para o fortalecimento e legitimidade da marca, as mulheres. Igualmente o programa Usinas do Trabalho, como uma tecnologia social com o propósito do alcance nacional via entidades parceiras, visa objetivos semelhantes.

Nesse sentido, conforme nossa pesquisa evidencia, a atuação da entidade que carrega o nome da marca Consul, nos cenários municipal e nacional, ultrapassa as relações mercantis passando a operar num universo simbólico para além da estrita utilidade pragmáticas dos eletrodomésticos. O exemplo do Consulado da Mulher mostra como a empresa, através de um programa de RSE racionalizado - cujo desempenho é avaliado sistematicamente pela Whirlpool - pode indicar novas lógicas na construção social da empresa. 


\section{CONSIDERAÇÕES FINAIS}

Os estudos sobre a inserção da empresa em programas de responsabilidade social tendem a indicar, conforme salienta Kirschner (2006; 2009), que as organizações não se limitam a coordenar e manter recursos econômicos, humanos e técnicos. A nova sociologia econômica, ao compreender a empresa como uma construção social, entende que a sua existência vai além de seu papel como mero organismo comercial. De fato, as empresas sofrem influências do meio socioeconômico que, por vezes, não são orientadas por escolhas racionais. Afirmar que as ações econômicas e as instituições econômicas são enraizadas socialmente, no âmbito dos estudos da RSE, é sobretudo, compreender que os atores sociais avaliam as empresas conforme o crivo ideológico ou ainda, por convenções sociais no sentido proposto por Weber (1991).

Nesse sentido, quando falamos em um aparente paradoxo entre a empresa capitalista e os recursos dirigidos à promoção da economia solidária destacamos que não há, de fato, uma contradição no quadro da RSE. Ao incorporarem elementos das agendas sociais e éticas, as organizações buscam estabelecer relações fundamentais para a sustentabilidade e a legitimidade de suas próprias ações econômicas. A Nova Sociologia Econômica em sua vertente política (FLIGSTEIN, 2001) nos ajuda a entender a RSE como uma ferramenta de gestão que permite a estabilidade das empresas em cenários de incerteza e contingência da ação individual, a saber, os cidadãos que consomem e participam dos mercados, que nem sempre são orientados apenas por escolhas racionais (adequação meios e fins).

Portanto, nessa comunicação associamos as práticas de RSE como uma tentativa da empresa em promover - em vários níveis - um diálogo com atores relevantes para a própria estabilidade a médio e longo prazo dos empreendimentos econômicos. Na dinâmica das transformações das empresas na esfera mercantil e no próprio processo de fusão, incorporação e "financeirização" das instituições empresariais, a RSE opera como uma "ferramenta de gestão" (GRÜN, 2009; ALOUCHE et al, 2004). Nesse sentido, os relatórios de sustentabilidade, os códigos de ética e a promoção da inserção do empresariado na agenda das políticas sociais contemporâneas são mecanismos pelos quais a empresa se relaciona com a sociedade, com os movimentos sociais contestatórios, com os consumidores, com a mídia, com os acionistas e com os demais segmentos sociais. A afirmação equivale a dizer que o estudo dessa posição do setor torna-se imprescindível para entender porque as empresas se vem hoje compelidas a obter lucros de uma determinada maneira, em particular através da 
transformação de questões da agenda social e política, ou seja dos movimentos sociais contestatórios, em ferramentas de gestão (BARBOSA, 2002). Da mesma forma, pensar a RSE como parte integrante da governança corporativa indica que, no bojo do processo de "financeirização" das empresas, os acionistas, inclusive os minoritários podem ter maiores acessos a fontes de informação sobre a atuação das empresas no meio sociopolítico e, portanto, maior poder de reflexão e orientação sobre onde direcionar seus investimentos.

O estudo sobre o Instituto Consulado da Mulher demonstra que os programas de RSE não se configuram como ações de filantropia social estritamente. De fato, nossa pesquisa esforçou-se em demonstrar que a criação da entidade representa o estágio ulterior de um processo de racionalização das ações sociais da empresa. Até o surgimento da iniciativa, as atividades restringiam-se às doações isoladas, sem foco ou metodologias de aplicação e avaliações. A antiga "filantropia empresarial” transformou-se em ações programadas e sistemáticas de apoio ao desenvolvimento social, incorporadas à lógica do "planejamento estratégico" das corporações. A afirmação equivale a dizer que a responsabilidade social das empresas existe antes mesmo da criação do conceito. No entanto, por mais que a empresa apresente uma trajetória de ações voltadas à comunidade (ou uma cultura da empresa, nesse sentido), foi, com a aquisição da Multibrás pela Whirlpool - no sentido de concentração de capital e recursos - que a instituição se preocupou em alinhar os programas sociais com as estratégias mais amplas da corporação. $\mathrm{O}$ aumento da visibilidade da Whirlpool em âmbito global e, sobretudo, os impactos sociais e ambientais do processo produtivo tendem a estabelecer a necessidade uma "gestão de risco social" ou ainda de "reputação global" da marca, no sentido de administração dos processos de contestação pública pelos chamados stakeholders ou como preferimos dizer, o tecido social onde a empresa se insere.

Por fim, ressalta-se a importância do papel da regulação estatal no âmbito das ações e discursos da RSE. Como vimos, os órgãos governamentais estimulam e promovem a inserção do setor empresarial em atividades que, em tese, visam o desenvolvimento social e a cidadania num claro indicativo de novas lógicas no trato da questão pública brasileira, em consonância como o modelo econômico neoliberal. São questões relevantes que, quando postas à luz das ciências sociais, demonstram as mudanças em curso na sociedade contemporânea, bem como os desafios que se apresentam para nossas reflexões. Como sugestão para agendas de pesquisas posteriores, sugerimos pesquisas comparativas para delimitar as atuações das empresas em países desenvolvidos e em desenvolvimento - ao longo da cadeia produtiva - para entender em que medida o postulado da construção social 
dos mercados é relevante para definir as "estratégias" de atuação no âmbito da RSE em contextos sociopolíticos distintos.

\section{Agradecimentos:}

O artigo sintetiza e destaca os principais resultados das pesquisas de Monografia em Ciências Sociais e Dissertação de Mestrado em Sociologia Política pela Universidade Federal de Santa Catarina. Somos gratas ao grupo de trabalhadores e trabalhadoras dessa instituição, em particular o grupo docente e servidores públicos do Programa de Pós-Graduação em Sociologia Política (PPGSP-UFSC). Agradecemos a Coordenação de Aperfeiçoamento de Pessoal de Nível Superior (CAPES) pelo financiamento das pesquisas, através da bolsa de estudos de mestrado. Somos gratas à Professora Cécile Raud (in memoriam) pelo legado, pela inspiração acadêmica e, sobretudo, por nos orientar na visão complexa da conduta humana, para além da dimensão utilitarista da vida social. Esse artigo é dedicado ao incansável trabalho da amiga e Professora Marcia da Silva Mazon (PPGSP-UFSC), uma das articuladoras da rede de Sociologia Econômica no Brasil.

\section{REFERÊNCIAS}

ALBARELlO L. et al. Práticas e Métodos de Investigação em Ciências Sociais. Lisboa: Gradiva, 1997.

ALMEIDA, M. A Percepção da Responsabilidade Social nas Relações de Trabalho. Florianópolis, 2006. 74f. Monografia (Graduação em Ciências Sociais). Curso de Ciências Sociais Centro de Filosofia e Ciências Humanas. Universidade Federal de Santa Catarina, Florianópolis, 2006.

ALLOUCHE, José; HUAULT, Isabelle; SCHMIDT, Géraldine. Responsabilité Sociale des Enterprises: La mesure détournée? In: ANAIS DU CONGRÈS AGRH 2004. Disponível em: https://basepub.dauphine.fr/bitstream/handle/123456789/1143/Allouche_Huault_Schmidt.pdf ?sequence $=2$ Acesso em 26 nov. 2014.

BARBOSA, L.Globalização e Cultura de Negócios. . In KIRSCHNER, A.; GOMES, E.; CAPPELLIN, P. (Orgs.). Empresa, empresários e globalização. Rio de Janeiro: FAPERJ e Relume Dumará, 2002, pp.2011-225.

BARDIN, L. Análise de Conteúdo. São Paulo: Edições 70, 2011.

BENNETT, Craig. Muito além da tinta verde. Guia Exame de Sustentabilidade. $11^{\circ}$ edição. São Paulo: Ed. Abril, Nov. 2010, pp. 106-110.

BERNOUX, P. La Sociologie des Entreprises, Paris: Editions du Seuil, 1995.

BRESSER PEREIRA, L. \& GRAU, N. O Público Não-Estatal na reforma do Estado. Rio de Janeiro: FGV, 1991. 
BOURDIEU, P. O Poder Simbólico. Lisboa: Difel, 1989.

COLEMAN, J. Foundations of Social Theory. Cambrigde-Massachutts: The Belknap Press of Harvard University Press, 1990.

CAPPELLIN, P. Ações afirmativas, gênero e mercado de trabalho: a responsabilidade social das empresas na União Europeia. In Rocha, Maria Isabel Baltar (org.). Trabalho e Gênero: Mudanças, Permanências e Desafios. Campinas: ABEP, NEPO/UNICAMP e CEDEPLAR/UFMG/São Paulo: Ed. 34, 2000. 384 p.

CAPPELLIN, P. et al. As Organizações empresariais e a responsabilidade das empresas. In KIRSCHNER, A.; GOMES, E.; CAPPELLIN, P. (Orgs.). Empresa, empresários e globalização. Rio de Janeiro: FAPERJ e Relume Dumará, 2002, pp. 253-278.

CRANE, A. et. al. The Oxford Handbookof Corporate Social Responsibility. New York: Oxford University Press, 2008.

DUARTE, José Rodrigues; JACQUES, Caroline. Considerações sobre a Responsabilidade Social das Empresas: configurações, valores e interesses. In: VII Workshop Empresa, Empresários e Sociedade, Florianópolis. 2010. Anais do VII Workshop Empresa, Empresários e Sociedade. Florianópolis.

DURSTON, J. Que é el Capital Comunitário? Santiago de Chile: CEPAL/ECLAC, 2000.

GOMES. M. Empregabilidade nos tempos de reestruturação e flexibilização. Trajetórias de trabalho e narrativas de ex-empregados do setor elétrico brasileiro. Rio de Janeiro, 2002. 358 f. Doutorado (Sociologia e Antropologia). Programa de Pós Graduação em Sociologia e Antropologia. Universidade Federal do Rio de Janeiro, Rio de Janeiro, 2002.

FLIGSTEIN, N. Mercado como política: uma abordagem político-cultural das instituições de mercado. Revista Contemporaneidade e Educação, V.6, N.9, 2001, pp.26-55.

FUNDAÇÃO BANCO DO BRASIL. O que é Tecnologia Social. Disponível em < http://www.fbb.org.br/tecnologiasocial/o-que-e/tecnologia-social/o-que-e-tecnologiasocial.htm> Acesso em 26 nov. 2014.

GARRIGA, E; MELÉ, D. Corporate Social Responsibility Theories: mapping the Territory. Journal of Business Ethics. V.53, N. 01, 2004, pp.51-71.

GEERTZ, C. A Interpretação das Culturas. Rio de Janeiro: LTC, 2008.

GOLDSTEIN, I. Responsabilidade Social. Das grandes corporações ao terceiro setor. São Paulo: Ática, 2007.

GROS, D. Desafios da responsabilidade. As atualizações entre práticas e discursos. In: GROS, Denise et alii (Eds). Empresas e grupos empresariais: atores sociais em transformação. Juiz de Fora: Ed. UFJF, 2005, pp. 43-61. 
GRÜN, R. Brasil e brasileiros na globalização financeira. In: CONGRESSO NACIONAL DE SOCIOLOGIA ECONÔMICA, 2009, Florianópolis. Anais do Congresso Nacional de Sociologia Econômica. Florianópolis.

IGLESIAS, E. In: La Agenda ética pendiente de América Latina. Bernardo Kliksberg (compilador), Buenos Aires e México D.F.: Fondo de Cultura Económica, Banco Interamericano de Desarrollo, 2005.

INSTITUTO CONSULADO DA MULHER. Instituto gera trabalho e renda em Rio Claro e Joinville. Disponível em: http://consuladodamulher.org.br Acesso em: 04 maio 2014.

JACQUES, Caroline. Responsabilidade Social Empresarial: Um Estudo sobre a Prática Socialmente Responsável a partir da Empresa Multibrás S.A - Joinville/SC. 54f. Monografia (Graduação em Ciências Sociais). Curso de Graduação em Ciência Sociais. Universidade Federal de Santa Catarina, Florianópolis, 2007.

JACQUES, Caroline. A Construção Social da Empresa em tempos de Responsabilidade Social Corporativa: um estudo de caso a partir da Whirlpool S.A. 142f. Dissertação (Mestrado em Sociologia Política) - Programa de Pós Graduação em Sociologia Política da Universidade Federal de Santa Catarina, Florianópolis, 2010.

JACQUES, Caroline. A dádiva nas relações entre empresas e sociedade: uma análise da responsabilidade social empresarial sob o enfoque sociológico. Revista Em Tese, v.7, n1/2. 2010b, pp.42-55.

JACQUES, Caroline. Entre a racionalidade econômica e a coesão social. Um estudo sobre o Instituto Consulado da Mulher - Joinville/SC. In: IX REUNIÃO DE ANTROPOLOGIA DO MERCOSUL, Curitiba. Anais da IX Reunião de Antropologia do Mercosul, 2011, Curitiba.

KIRSCHNER, A. A sociologia da empresa e responsabilidade social das empresas. Revista Nueva Sociedad. N. 202. mar/abri, 2006. Disponível em: http://www.nuso.org/upload/articulos/3343 2.pdf Acesso em 02 maio 2014.

KIRSCHNER, A. Considerações sobre a responsabilidade social das empresas em contextos de desigualdade e exclusão. Política \& Sociedade. V.8, N.15, 2009, pp.99-116.

PAOLI, M. Empresas e responsabilidade social: os enredamentos da cidadania no Brasil. In: Democratizar a democracia: os caminhos da democracia participativa (org) SANTOS, Boaventura de Sousa. Rio de Janeiro: Civilização Brasileira, 2002.

RAUD, C. Indústria, Território e Meio Ambiente no Brasil. Perspectivas da Industrialização descentralizada a partir da análise da experiência catarinense. Florianópolis: Editora da UFSC; Blumenau: Ed. da FURB, 1999.

RAUD-MATTEDI, C. A Construção Social do Mercado em Durkheim e Weber: Análise do Papel das Instituições na Sociologia Econômica Clássica. Revista Brasileira de Ciências Sociais. V. 20, N. 57, fevereiro, 2005. Disponível em < http://www.scielo.br/scielo.php?

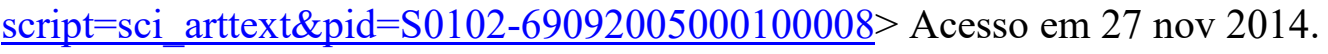


RUGGIE, J. Just Business: Multinational Corporations and Human Rights. Harvard Univ., former UN Special Representative on business \& human rights, 2013.

SAINSAULIEU, R. Sociologie de l'Organisation et de l'Entreprise, Presse de la Fondation Nationale des Sciences Politiques \& Dalloz, Paris, 1987.

STEINER, P. A Sociologia Econômica. São Paulo: Atlas, 2006.

TORQUATO, J. A Responsabilidade Social em duas unidades do Setor Elétrico Brasileiro: Relações, Significados e Avaliações. Florianópolis: 140f. Dissertação (Mestrado em Sociologia Política) - Programa de Pós Graduação em Sociologia Política da Universidade Federal de Santa Catarina, Florianopolis, 2007.

ZACHARIAS, O. SA 8000 Responsabilidade Social NBR 16000. São Paulo: Editora EPSE, 2004.

WEBER, Max. Economia e Sociedade. Brasília, Editora da UnB, 1991.

WHIRLPOOL (2007-2008). Relatório de Sustentabilidade 2007-2008. Disponível em http://www.multibras.com.br/site/files/c308_relatorio.pdf Acesso em: 08 set. 2014

WHIRLPOOL (2009-2010). Relatório de Sustentabilidade 2009-2010. Disponível em http://www.whirlpool.com.br/site/p/responsabilidadesocial/relatoriodesustentabilidade Acesso em: 09 out. 2014. 